\title{
COMPOSIÇÃO: ANÁLISE E SÍNTESE, SISTEMAS, PRINCÍPIOS E TÉCNICAS
}

Ricardo Bordini

\begin{abstract}
Resumo
Investiga-se a atividade compositiva partindo-se do pressuposto que processos de síntese e análise interagem simultânea e complementarmente. Abordam-se aspectos relacionados ao pensamento compositivo e sua natureza, sua relação com a notação musical e com a conspecção da ordem sistêmica. Discorrese sobre os princípios básicos do sistema tonal. Apresenta-se um caso analítico estruturado nesse sistema. Expõem-se princípios básicos de um sistema não tonal, a saber, o espaço de encadeamentos atonal para tricordes. Formulase um caso sintético originado pelo caso analítico, porém transportado para um sistema não tonal.
\end{abstract}

\section{Palavras-chave:}

Composição; Síntese e Análise Musical; Princípios de Sistemas Tonais e Não Tonais; Processos Compositivos.

\section{INTRODUÇÃO}

Nesse artigo aborda-se o processo compositivo entendido aqui como resultado de processos simultâneos de síntese e de análise. Não se pretende esgotar o tópico senão apenas trazer ao iniciante de composição alguma informação quiçá útil. Abordase tão somente música que usa a notação musical tradicional e não se oferecem citações copiosas (com o perdão do mau trocadilho) posto que se trata apenas da visão autônoma do autor que já não sabe mais se o que pensa foi tirado de outrem ou se pensou por si mesmo, de sorte que não se pretende reclamar autoria. ${ }^{1}$

Como pensa o compositor? Como ele raciocina com sons? Como se organizam e se comportam sistemas musicais diferentes? São tópicos de pesquisa em várias áreas cujos resultados proveem o compositor contemporâneo de literatura abundante.

\section{Abstract}

Compositional activities are supposed to share synthesis and analytical processes that act simultaneously. Compositional reasoning and its nature, notation and systemic order are approached. Basics of tonal systems are stated as preparation for an analytical case study. A nontonal system - an expanded atonal voice-leading space for trichords - is discussed as a basis for another case study rooted in the previous analytical one.

Keywords:

Musical Composition; Synthesis and Analysis;

Basics of Tonal and Non-tonal Systems;

Compositional Processes.

O professor de composição (quer-se crer) necessita a todo instante manter um duplo cuidado sobre o trabalho de seus diletos pupilos: 1) como a superfície musical se mantém interessante e eficiente, e 2) como a estrutura subjacente coere com a superfície, sustendo-a e conduzindo-a. Faz isso mediante processos conjuntos de síntese e análise: por um a técnica, pelo outro a imaginação.

\section{SÍNTESE E ANÁLISE: O PENSAMENTO COMPOSITIVO}

O termo síntese tem como sinônimos: composição, justaposição, combinação, mistura, refere-se ao processo pelo qual as partes são juntadas para formar o todo. Análise tem como sinônimos: dissolução, solução, libertação, fim, refere-se ao processo de separar o todo em suas partes constituintes. São entendidos como processos complementares, de via dupla: de um lado está 
o todo e do outro lado estão as partes. De um chega-se ao outro e vice-versa.

Já se abordou esse tópico em outra ocasião e repete-se aqui que: para a música que pode ser escrita, a partitura é sua melhor análise "pois ali é que está mais claramente explicado e prescrito como as diferentes partes coerem e se relacionam entre si e com o todo" e acrescenta-se: como o todo deriva-se em suas partes" (BORDINI, 1994, p. 11). E como se costuma dizer: a soma das partes não equivale ao todo ou o todo é maior do que a soma das partes (SCHEIRER, 1997).

Compor é pensar com sons (notas). Encontrar uma lógica, um padrão, um princípio, sejam quais forem, em um sistema musical, é pensar por suas próprias leis. Essa lógica pode derivar do próprio sistema musical, de um modelo extramusical ou do ideário do compositor, por analogia ou metáfora, mormente de ambas.

Absteve-se aqui de um aprofundamento terminológico necessário. Lógica supõe raciocínio e este é um "process for arriving at a conclusion as to whether or not a given 'proposition' is true" (HOGAN, 1997, p. 25)2. Mas no caso da música, qualquer proposição pode ser verdadeira e, portanto, está-se diante de outro tipo de raciocínio.

Também não se pretende discutir relações entre música e linguagem aqui, pois a pesquisa comparativa nesse campo anima-se pela tensão entre duas perspectivas: "one that emphasizes the differences between music and language, and one that seeks commonalities" (PATEL, 2008, p. 4) ${ }^{3}$. Identifica-se esse trabalho mais com aquela sem, entretanto, negar esta. Se aceita como premissa que: "music and speech have one very obvious difference in their sound category systems. Although pitch is the primary basis for sound categories in music (such as intervals and chords), timbre is the primary basis sound for categories of speech (eg. vowels and consonants)" (PATEL, 2008, p. 9) ${ }^{4}$.

O pensamento musical criativo está inexoravelmente interligado à notação musical. Muitas das decisões que o compositor toma dependem em alguma instância da notação. Ao pensar-se numa nota (mesmo abstratamente ouvindo um som musical) pensa-se imediatamente em como registrá-lo. E a notação musical oferece fundamentalmente dados em conformidade com a acústica: que nota é, quanto tempo dura e qual sua intensidade (para um modelo da estrutura do som musical ver Capítulo 2 de MEYER, 2009). Similarmente, isso é tudo o que decodificamos no nível da fisiologia do ouvido interno; todo o resto, incluindo o timbre, é elaborado posteriormente no nível cerebral e depende de aspectos os mais diversos: psíquicos, fisiológicos, culturais etc.

Entretanto, há que se considerar (e o professor de composição deve atentar para) as diferenças entre a notação e a execução da qual depende a fruição musical. Mais uma vez, foge do escopo do artigo, a investigação das implicações e a correlação entre notação e interpretação musical.

O ponto de interesse aqui é a relação entre a composição (como processo sintético) e a análise, ambas em constante interação. O labor compositivo processa-se basicamente em instâncias de decisão que incluem, no nível sintético: que nota é, quanto tempo dura, qual vai junto ou depois dela, quem toca ou canta, quão forte ou piano etc. Simultaneamente, no nível analítico, precisa conferir se as decisões tomadas coerem entre si e como resultam as partes quando postas juntas. Essas decisões dependem circunstancialmente das leis internas do sistema e dentre as opções de escolha, quando as há, avalia e julga o compositor segundo requisitos estéticos, aderência a um planejamento prévio quando há ou, por gosto pessoal mesmo. E não se precisa explicar nada, nem mesmo justificar porque fez essa ou aquela escolha. Pode compor uma nota depois da outra ou pode usar técnicas para configurar uma peça inteira de uma só vez como propõe Worinem (1979, p. 157-162). Pode escrever a peça inteira do início ao fim sem alterações ou pode reescrever inúmeras vezes passagens inteiras até estar satisfeito. Os perfis e os processos são muitos, porém "each composer asserts what music is through his works; and when he speaks of the nature of music, it is from his direct experience of making it" (WUORINEM, 1979, p. viii) ${ }^{5}$.

\section{O SISTEMA TONAL}

Os princípios que regulam o sistema tonal (e o modal do qual deriva) têm sido bastante estudados desde há muito e ainda hoje se renovam em teorias 
que tentam compreendê-los melhor (TYMOCZKO, 2011). A centralidade, tão importante para a tonalidade, a pós-tonalidade triádica e abordagens neoriemannianas confirmam a importância atual do tópico (STRAUS, 2010, p. 172-183). O que se especula aqui nada mais é do que especulação. Nada se quer provar nem se requer autoria. 0 que todos concordam é que no sistema tonal as unidades harmônicas baseiamse na superposição de terças, quer dizer, "built of thirds" (KOSTKA, 2015, p. xiii) ${ }^{6}$. É fácil verificar isso simplesmente olhando para uma escala disposta em um pentagrama: notas que estão sobre linhas consecutivas estão separadas por terças assim como as que estão em espaços. Não importa quantas terças estejam empilhadas, ao começar-se numa linha, todas as outras estarão em linhas, sendo o mesmo princípio válido para os espaços (não se considera aqui inversões, caso em que linhas e espaços misturar-se-ão; aliás, uma boa indicação para localizar inversões). Outra característica evidente é que se trata de um sistema redundante: superpondo-se terças para formar tríades, já os três primeiros acordes esgotam a escala com duas duplicações; todas as demais tríades são redundantes. Considerando acordes de sétima, bastam os dois primeiros e a escala já se esgota.

O que importa então não são as notas nem os intervalos, mas a ordem que tomam no sistema. Por exemplo: o quinto grau da escala quando está colocado como quinta do acorde construído sobre o grau da tônica é descartável, entretanto, quanto está como fundamental do acorde de dominante é essencial, à ponto de definir a própria tônica e é a nota comum entre os dois acordes. O primeiro grau da escala quando está colocado como fundamental do acorde da tônica define a própria tonalidade, contudo, quando está como a quinta do acorde da subdominante, é descartável e é a nota comum entre os dois acordes. Por isso, talvez o baixo seja tão importante para o sistema.

Para deslocar-se no círculo de quintas basta alterar ascendentemente o quarto grau para mover-se no sentido horário (subir quintas ou descer quartas) ou, alterar descendentemente o sétimo grau para mover-se no sentido anti-horário (descer quintas ou subir quartas, o que dá no mesmo). Necessárias ao caso que se estudará mais adiante se fixa por ora o caso das quintas descendentes. Para descer uma quinta basta acrescer-se uma sétima menor à tríade formada sobre o grau da tônica, ou seja, o sétimo grau da escala alterado descendentemente. Como a resolução será na tônica da próxima tonalidade (vizinha), basta acrescentar o sétimo grau da nova escala sobre aquele acorde e movese então para a próxima tonalidade e assim por diante. $O$ interessante é saber quando se atinge o encadeamento por trítono e onde colocá-lo na progressão. Em geral termina-se a progressão antes de chegar nele. Por ora, basta dizer que se quisermos sair de uma determinada tônica e chegar a ela novamente, subindo no círculo de quintas, o encadeamento por trítono estará no final da progressão (progredir no círculo de quintas é progredir saltando entre graus da própria escala - com funções secundárias). Mas partindo-se do grau da dominante, o encadeamento por trítono estará na metade da progressão. O leitor carente de mais informações sobre o sistema tonal pode buscá-las em http://musica.ufba.br/bordini/ ap_art ao passo que o leitor pré-claro já vai adiantando-se no texto.

\section{ANÁLISE DE CASO TONAL}

O Exemplo 1 mostra uma redução analítica dos compassos 87 a 91 do primeiro movimento do Concerto de Brandenburgo No. 3 de J. S. Bach. A instrumentação compreende três partes de violinos, três de violas, três de violoncelos, contrabaixo e cravo. A tonalidade é Sol maior e no compasso anterior ao que inicia o exemplo a tonalidade principal está enfatizada por um pedal de tônica e reforçada pela dinâmica forte. No compasso 87 há uma tonicalização (por acorde comum alterado) de Ré maior (a dominante de Sol) e uma escala descendente iniciando na nota Ré, no baixo, no terceiro tempo do compasso, sustenta uma progressão harmônica por círculo de quintas descendentes e termina no compasso 91 na nota Ré também, porém duas oitavas abaixo como parte de um acorde de Sib maior em primeira inversão, com dinâmica em piano. A função do Sib é de sexta napolitana do Lá menor que o precede e que será a tonalidade enfatizada a partir daí e confirmada no compasso 101 pela fórmula cadencial que caracteriza o movimento.? Lá menor é a tonalidade da supertônica, comum em Bach como centro tonal. Cria assim funcionalidades bastante contrastantes para a nota Ré e para os acordes dos quais a nota faz parte. 


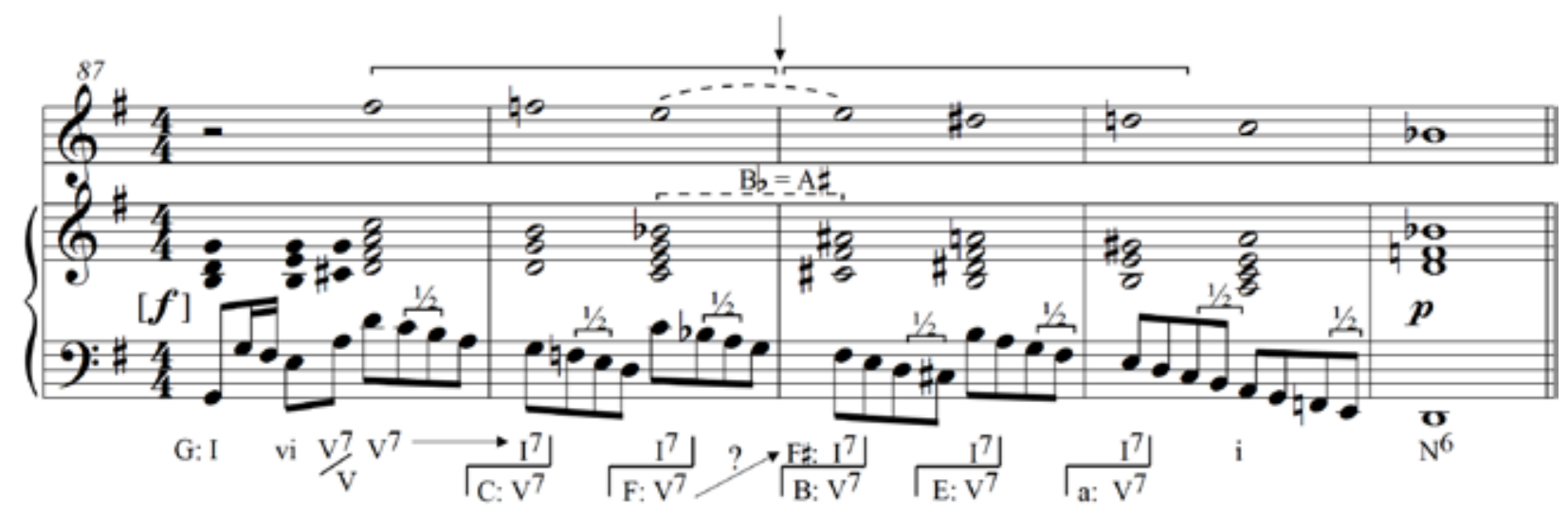

Exemplo 1 - Redução analítica dos c. 87-91; Concerto de Brandenburgo No. 3, I, de J. S. Bach. Fonte: Acervo de Ricardo Bordini.

Durante o percurso, saltos de sétima menor ascendentes modificam o curso da escala. Se a escala fosse escrita sem esses saltos, perpassaria quatro oitavas e não apenas duas. Paralelamente à escala diatônica descendente, outra escala cromática (com exceção das duas últimas notas que são diatônicas), de durações mais longas, se faz presente. Note-se a relação entre as duas: a cada quatro notas diatônicas do baixo há uma nota cromática no soprano; os intervalos alternamse formando intervalos de terça maior e sétima menor (compostas) consecutivamente. Observese também que no ponto onde a progressão encontra o trítono (Dó-Fáł) a terça de um e a sétima de outro são a mesma nota (Mi) ao passo que nos outros encadeamentos a terça e a sétima são graus cromáticos. $\mathrm{E}$ o Mi está justo no centro da progressão assim como o encadeamento do trítono. Ainda mais, depois do trítono a posição do semitom na escala diatônica transfere-se das segunda e terceira notas de cada grupo de quatro para as terceira e quarta notas. O trítono interrompe a sequência do círculo deslocando-a para o lado oposto e assim todos os graus da escala são usados como centros tonais. A progressão depois do Lá menor poderia voltar para Ré maior (ou menor como sugere o Fáł na escala), mas surpreendentemente atinge o Sib maior (no outro lado).

O encadeamento de acordes separados por trítono apresenta características interessantes: duas notas são comuns sendo: uma por enarmonia (no caso em apreço, Sib - Láł) e uma repetida (Mi); uma desce um semitom diatônico (Sol - Fáł) e outra sobe um semitom cromático (Dó - Dół). Não, não se ouve música assim, mas que é belo de observar-se é.

Escolhe-se esse excerto, tão simples e ainda assim tão rico, por apresentar características únicas, não encontradas no restante da peça. Sua sonoridade distinta alia-se à sua localização que, no movimento de 136 compassos, conclui justamente no segundo terço da obra (compasso 90 aproximadamente).

Pode-se fazer uma associação analógica desse pensamento musical e sua lógica - que deriva do próprio sistema tonal - com o parafuso de Arquimedes: mecanismo em que um parafuso (helicoide) gira dentro de um cilindro oco permitindo transferir mormente líquidos, de uma extremidade para outra num plano inclinado ou mesmo horizontal. Da mesma forma, o excerto transporta a estrutura do fluxo musical de um Ré para outro mais grave, porém as funções da mesma nota são diferentes (no início é ouvida como fundamental de Ré maior com sétima e no último como terça de Sib maior); como se estivessem em níveis diferentes depois de passarem rodando por quatro oitavas. Os saltos de sétima assemelham-se às voltas do parafuso que giram sempre no mesmo lugar transportando a matéria para a próxima volta. Outro paralelo pode ser estabelecido com a Waterfall (dentre outras gravuras)[ de Escher ${ }^{8}$. Especulações apenas? Sim, 


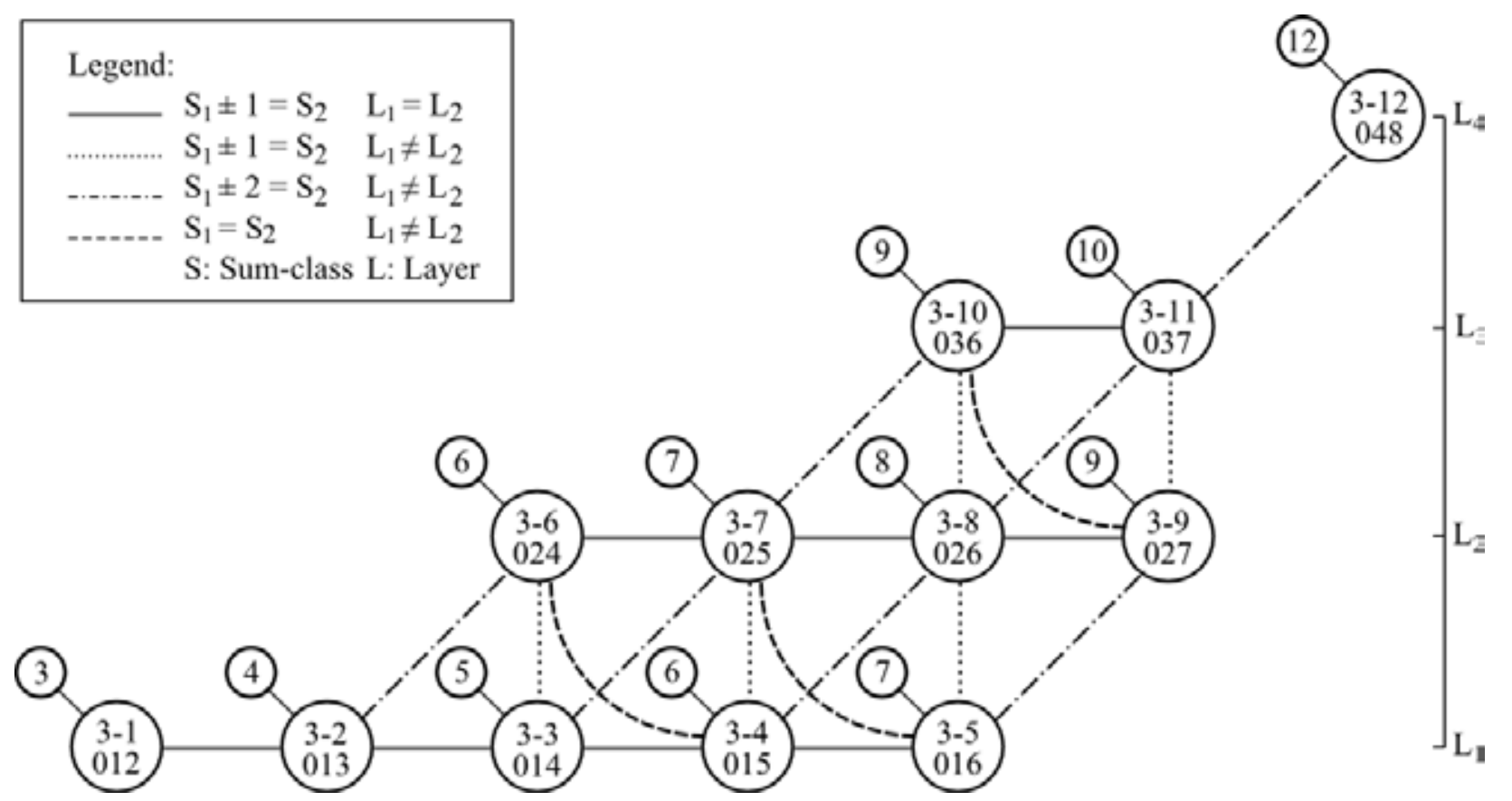

Figura 1 - Espaço expandido de encadeamentos atonal para tricordes. Fonte: Acervo de Ricardo Bordini.

mas não de todo desprezáveis. 0 exemplo musical dado, quer esteja associado ou não ao dispositivo físico ou à ilusão pictórica retro mencionados, ilustra dois expedientes que os compositores usam para suas sínteses: 1) partir de uma nota e chegar a ela própria, com outra função, através de divisões diversas - em geral em partes iguais - da oitava e 2) usar modelos externos ao sistema musical para amparar a estrutura.

\section{UM SISTEMA NÃO TONAL}

Sistemas diferentes devem produzir músicas diferentes. Entretanto, há um continuum entre os sistemas musicais, pois obviamente, operam todos sobre a mesma matéria. O que os diferencia é, em grande extensão, a ordem de organizarse o mesmo material. Música tonal cromática e música serial utilizam o mesmo universo de notas, porém, com resultados muito diferentes. A suposição de que a ordem é importante apenas para músicas seriais por exemplo, confirma-se equivocada porquanto mesmo no sistema tonal, ao mudar a ordem de superposição das terças em uma tríade, muda-se a natureza do acorde com implicações tonais bastante diversas, como por exemplo, mudar o modo abrindo possibilidades de modulação para tonalidades afastadas.

Sistemas não tonais (ou não modais) são suficientemente complexos para serem exauridos no escopo diminuto desse trabalho. Destarte, escolhe-se abordar o espaço de encadeamentos atonal para tricordes como sistema em foco, espaço esse que vai apresentado na Figura $1^{9}$.

Pode-se notar que é um pouco diferente daquele apresentado por Straus (2005, p. 111) baseado em Morris (1998, p. 175-208). Ele foi girado $90^{\circ}$ para a esquerda, tem números de classes de soma dentro de pequenos círculos ligados às classes de conjunto, tem índices de camada assinalados para cada linha de classes de conjuntos e tem conectores diferenciados ligando as classes de conjuntos ${ }^{10}$.

Como está proposto aqui, esse espaço de encadeamentos expandido tem as seguintes características: 1) usa exclusivamente classes de conjuntos em forma prima, significando que é um sistema OPTIC completo (ver CALLENDER; QUINN; TYMOCZKO, 2008), 2) não admite multiconjuntos $\left(\right.$ multisets) ${ }^{11}$ e 3 ) admite outras operações além 


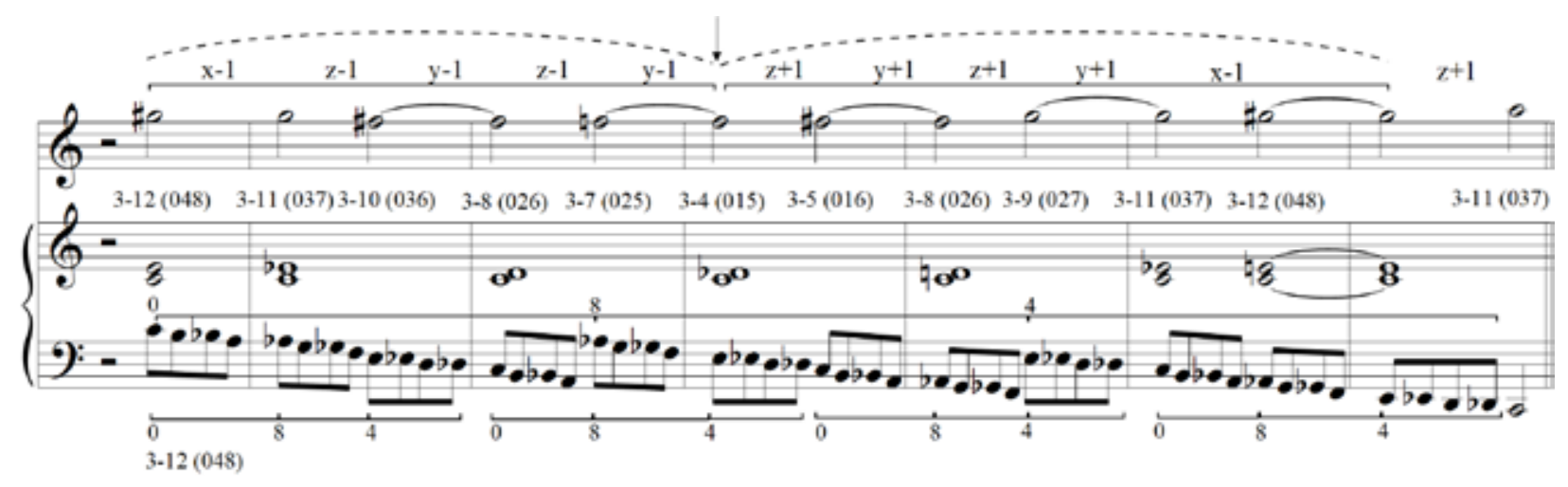

Exemplo 2 - Formulação sintética em sistema não tonal. Fonte: Acervo de Ricardo Bordini.

daquelas usadas comumente (para uma discussão mais complexa ver COOK, 2005).

Por definição, o espaço de encadeamentos é criado colocando-se próximas às classes de conjunto que estão separadas por semitom, por exemplo: Dó, Dó\#, Ré, um membro da classe de conjuntos 3-1 (012) e Dó, Dó\#, Ré\#, um membro da classe de conjuntos 3-2 (013) estão conectados no espaço de encadeamentos, porque o Ré do primeiro conjunto está separado por apenas um semitom do Ré\# do segundo conjunto.

Assim como o sistema tonal pode ser entendido como fundado no espaço linear de notas, o espaço de encadeamentos funda-se no espaço circular de classes de notas e deve-se entender que "pitch and pitch-classes are not separate and independent: pitch-class space is formed out of pitch space when we choose to ignore, or abstract away from, octave information" (TYMOCZKO, 2011, p. 30-31) $)^{12}$. Implicações dessa diferença vir-se-ão mais adiante.

Há vários caminhos (ou lógicas do sistema) para atravessar o - ou de circular dentro do - espaço de encadeamentos atonal para tricordes. Escolhese um que parte de 3-12 (048), a única classe de conjuntos tricordais (altamente redundante) que divide a oitava em partes iguais sem repetição, circula pelo espaço até 3-4 (015) como extremo oposto e retorna ao ponto de partida, por outra via, seguindo operações específicas.

\section{SÍNTESE DE CASO NÃO TONAL}

O Exemplo 2 ilustra uma aplicação de processo de síntese transportando a ideia analítica anterior para um sistema não tonal. Comenta-se a proposição relacionando-a com o caso analítico que the deu origem.

As operações que controlam o fluxo de circuitação no espaço de encadeamentos proposto seguem o seguinte padrão (ordem): parte-se de 3-12 (048), aplica-se ao primeiro membro da classe de conjuntos a operação $x-1$ movendo-o assim para 3-11 (037) ${ }^{13}$. Em 3-11 (037) opera-se z-1 movendo-o para 3-10 (036). Opera-se então y-1 movendo-o para 3-8 (026), classe essa que vai operar como um centro gravitacional para o espaço devido à sua posição central (ver a Figura 2). Opera-se z-1 e move-se de 3-8 (026) para 3-7 (025). Mais uma operação $y-1$ e move-se para 3-4 (015), chegando-se nesse ponto ao extremo oposto do ponto de partida. As operações foram todas negativas até aqui, significando de que se está comprimindo intervalos. A partir desse ponto, as operações agora serão positivas, ou seja, estáse expandindo intervalos, o que implicará em um retorno ao ponto inicial por outra via, passando, entretanto, ainda pelo centro 3-8 (026). Têm-se assim: 3-4 (015) operado por $z+1$ movendo-se para 3-5 (016), y+1 move-o para 3-8 (026), z+1 movendo-o para 3-9 (027) e, y+1 move-o para 3-11 (037). Note-se que só há uma maneira de retornar para 3-12 (048) e, portanto, as operações positivas enceram-se e aplica-se por 
fim a operação negativa inicial, $x-1$, para retornar ao ponto de origem ${ }^{14}$.

$\mathrm{Na}$ circuitação do espaço, com exceção da conexão diagonal entre 3-12 (048) e 3-11 (037), todas as demais operações alternam movimentos horizontais com verticais tanto na ida quanto na volta perpassando completamente o espaço (outra possibilidade seria evitar o centro em 3-8 (026) com resultados talvez mais interessantes, o que fica postergado para outra ocasião). Optou-se também por manter todas as classes de conjunto em forma prima de modo que o leitor pode acompanhar mais facilmente o fluxo; uma implicação adicional dessa decisão é a manutenção de uma nota comum entre todas as classes de conjunto, a saber, a classe de notas 0 (Dó). As outras classes efetuam movimentos cromáticos conjuntos, como resultado da própria organização do espaço.

Observa-se inicialmente que numa escala tonal, de cinco em cinco notas ascendentes (ou quatro descendentes como no caso de Bach) muda-se de posição no círculo de quintas. No caso ora em apreço, como a escala (régua) que se está usando divide a oitava em terças maiores: 3-12 (048), a escala cromática atinge seus pontos de inflexão de quatro em quatro notas, criando um paralelo com o caso anterior. Os saltos de sétima menor do exemplo anterior são substituídos pelos de sétimas maior (novamente como resultado da substituição de escalas diatônicas pela escala cromática). Similarmente ao exemplo tonal, sem os saltos, a escala estender-se-ia por cinco oitavas (quatro no caso tonal, sendo a oitava excedente novamente resultante da diferença entre as escalas). Além disso, o ponto central da progressão articula o descenso cromático retrogradando-o ascendentemente, característica essa que difere do exemplo tonal que mantém o movimento cromático descendente.

Finalmente, procurou-se preservar a mudança de função entre a nota inicial e a final da escala do baixo. Essa escala está articulada de modo a enfatizar a projeção da classe de conjuntos 3-12 (048) nela mesma, razão pela qual os saltos estão localizados onde estão, permitindo a inserção de quatro repetições da classe. Porém, o sistema tonal caracteriza-se por exibir funções tonais para as notas, o que não existe nesse sistema. Assim, o artifício encontrado foi mudar a classe de conjuntos final de modo que a sonoridade resultante oferecesse uma clara noção de contraste. A solução para manter o paradigma da proximidade no espaço de encadeamentos foi operar $z+1$ trazendo a classe de conjuntos de volta para 3-11 (037). A última nota Ré do exemplo tonal era a terça do acorde de Sib maior (um membro da classe de conjuntos 3-11 (037)) e aqui não é diferente: o Dó é a terça do Lá menor (um membro da classe de conjuntos (037), igualmente).

\section{CONCLUSÃO}

Sistemas diferentes devem produzir músicas diferentes mesmo compartilhando a mesma matéria. Muitas propriedades podem ser mantidas entre sistemas diferentes, outras se modificam ao migrarem de um para outro e outras ainda podem não existir em um ou outro. A ordem que está no fulcro do sistema é quem determina os padrões que pode produzir.

Procurou-se mostrar, sabendo-se de antemão ser talvez impossível, como processos de síntese e análise complementam-se no fazer compositivo. o compositor lastreia-se tanto em um quanto em outro para tomar as decisões que formularão a música que cria. A superfície musical e sua estrutura interna estarão sempre dependentes da técnica e da imaginação do compositor.

Fez-se no exemplo não tonal o que poderia vir a ser uma redução analítica de uma música que ainda não foi escrita. Descreveu-se o processo de síntese que poderia vir a organizar tal música. Quantas músicas podem desdobrar-se do modelo é coisa indizível. Do que sempre estar-se-á diante é de padrões (sistemas e ordens), muitos dos quais "estranhos", formando inesgotáveis entrelaçamentos como numa "eternal golden braid" (HOFSTADTER, 1999) ${ }^{15}$.

\section{NOTAS}

1. Armando Albuquerque, Débora Katz, Bruno Kiefer, Cristina Gerling e Celso Loureiro Chaves, com quem estudei composição, harmonia e análise no Instituto de Artes da UFRGS, certamente detêm créditos. Jamary Oliveira, com quem estudei por mais tempo durante o mestrado e o doutorado na UFBA detém o crédito pelo que quer que haja de bom nesse trabalho e a quem dedico agradecimentos e admiração por ser quem é. 
2. Processo para concluir se ou não uma dada "proposição" é verdadeira.

3. Uma que enfatiza as diferenças entre música e linguagem, e uma que busca semelhanças.

4. Música e fala têm uma diferença óbvia em seus sistemas de categorias de sons. Embora a altura [das notas] seja a base primária para as categorias de sons na música (tais como intervalos e acordes), o timbre é a base sonora primária para as categorias da fala (por exemplo, vogais e consoantes).

5. Cada compositor avalia o que a música é pelas suas obras; e quando ele fala da natureza da música, é pela sua experiência direta de fazê-la.

6. Construído de terças. Kostka usa o termo "tertian" sem correspondente em português. Sugere-se traduzir por tercil (um termo derivado da estatística).

7. Nota-se o abandono da sequência cromática no final da progressão. Depois do Mi maior, seguindose o círculo de quintas, a tonalidade deveria ser Lá maior. Mas Bach retorna ao acorde diatônico em Sol maior de Lá menor dando ainda mais relevância ao Sib como sexta napolitana, que de outro modo não teria o mesmo efeito.

8. Ver o parafuso de Arquimedes em: http:// en.wikipedia.org/wiki/Archimedes 27_screw e da Waterfall de Escher em: http://www.mcescher. com/gallery/most-popular/waterfall/

9. Abordar-se-ão espaços para tetra, penta e hexacordes em trabalhos futuros. Resultados parciais de pesquisa em andamento estão em http://musica.ufma.br/bordini/evls/

10. Pressupõe-se que o leitor esteja familiarizado com a Teoria Pós-tonal, ou ao menos com os fundamentos da Teoria dos Conjuntos de Classes de Notas. Caso contrário, recomenda-se a leitura de Straus (2005 em inglês ou 2013 em português).

11. Multiconjuntos (multisets) são conjuntos que permitem a repetição de classes de notas, por exemplo, (001) é um deles.

12. Notas e classes de notas não são separadas ou independentes: o espaço de classes de notas é formado do espaço de notas quando escolhemos ignorar, ou remover, a informação da oitava.
13. Adverte-se ao leitor para não se deixar enganar pela forma prima dessas duas classes de conjuntos. Aparentemente há dois semitons separando as classes: 3-12 (048) e 3-11 (037) e, portanto, não deveriam estar conectadas no espaço de encadeamentos. Porém, observe-se que ao aplicar-se a operação x-1 a 3-12 (048) obtém-se $[B, 4,8]$ cuja forma prima é 3-11 (037). Operou-se assim apenas um membro e não dois como aparenta a forma prima (thank you so much, Straus).

14. Pode-se acompanhar o fluxo da circuitação efetuado pelas operações na Figura 1.

15. Eterna trança dourada.

\section{REFERÊNCIAS}

BACH, Johann S. Brandenburg Concerto No. 3. London: Eulenburg, 1984.

BORdINI, Ricardo Mazzini. Do Que Pudera Lembrar-se 0 Barqueiro Cujo Barco Era a Lua. 1994. 160 f. Dissertação (Mestrado) - Curso de Música, Universidade Federal da Bahia, Salvador, 1994.

CALLENDER, Clifton; QUINN, Ian; TYMOCZKO, Dmitri. Generalized Voice-Leading Spaces. Science, [s.I.], v. 320, p.346-348, 2008.

COHN, Richard. Square Dances with Cubes. Journal of Music Theory, [s.l.], v. 42, n. 2, p.283-296, 1998.

COHN, Richard. A Tetrahedral Graph of Tetrachordal Voice-Leading Space. Music Theory Online, [s.l.], v. 9, n. 4, p.1-19, 2003.

COOK, Robert C. Parsimony and Extravagance. Journal Of Music Theory, [s.l.], v. 49, n. 1, p.109140, 2005.

HOFSTADTER, Douglas R. Gödel, Escher, Bach: an Eternal Golden Braid. New York: Basic Books, 1999. Edição comemorativa do vigésimo aniversário.

HOGAN, James P. Mind Matters: exploring the world of artificial intelligence. New York: Del Rey, 1997.

KOSTKA, Stefan; PAYNE, Dorothy; ALMÉN, 
Byron. Tonal Harmony with an Introduction to Twentieth-Century Music. 7. ed. New York: Mcgraw-hill, 2013.

MEYER, Jürgen. Acoustics and the Performance

of Music: Manuals for Acousticians, Audio Engineers, Musicians, Architects and Musical Instrument Makers. 5. ed. New York: Springer, 2009. Tradução: Uwe Hansen.

PATEL, Aniruddh D. Music, Language, and the Brain. New York: Oxford, 2008.

SCHEIRER, Eric. Music, Gestalt, and Computing. 1997. Resenha do livro Music, Gestalt, and Computing: Studies in Cognitive and Systematic Musicology, editado por Marc Leman, traduzida por Ricardo M. Bordini. Disponível em: <http:// musica.ufma.br/bordini/ comp7/gestalt/res01. htm>. Acesso em: 06 ago. 2015.

STRAUS, Joseph N. Introdução à Teoria Póstonal. 3. ed. Salvador, São Paulo: Edufba e Unesp, 2013. Tradução: Ricardo M. Bordini.

Introduction to Post-Tonal Theory. 3. ed. New York: Pearson, 2005.

WUORINEN, Charles. Simple Composition. New York: Longman, 1979.

\section{Sobre o autor}

Ricardo Mazzini Bordini possui graduação em Composição pela Universidade Federal do Rio Grande do Sul (1986), graduação em Regência pela Universidade Federal do Rio Grande do Sul (1987), mestrado em Música pela Universidade Federal da Bahia (1993), doutorado em Música pela Universidade Federal da Bahia (2003) e estágio pós-doutoral na University of California at Santa Cruz (2012). Atualmente é professor Associado I da Universidade Federal do Maranhão. Tem experiência na área de Artes, com ênfase em Composição Musical, atuando principalmente nos seguintes temas: análise musical, teoria póstonal, música brasileira, composição musical, execução musical, informática e hipermídia em música, espaço de encadeamentos atonal, e composição algorítmica. 